\begin{tabular}{|c|c|c|}
\hline $\begin{array}{l}\text { PKS } \\
\text { PUBLCC } \\
\text { KNOLLEDEG } \\
\text { PROECC }\end{array}$ & $\begin{array}{c}\text { Revista de GEOGRAFIA } \\
\text { (RECIFE) } \\
\text { http://www.revista.ufpe.br/revistageografia }\end{array}$ & 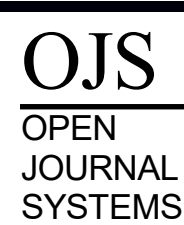 \\
\hline
\end{tabular}

\title{
PATRIMÔNIO: ENTRE ESCALAS GEOGRÁFICAS E ESPAÇOS POLÍTICOS
}

\author{
Dirceu Cadena de Melo Filho ${ }^{1}$ \\ ${ }^{1}$ Doutor em Geografia pela Universidade Federal do Rio de Janeiro. Email: dirceucadena@gmail.com
}

Artigo recebido em 28/08/2017 e aceito em 01/10/2017

\begin{abstract}
RESUMO
Recentemente a geografia passou a considerar a patrimonialização na compreensão das transformações espaciais. Apesar das diversas contribuições dos geógrafos envolvidos com o tema nota-se uma ausência de estudos sobre os aspectos políticos do patrimônio. O presente texto espera contribuir a partir da geografia política com as aproximações entre patrimônio e espaço, avançando na aplicação dos conceitos de escala geográfica e de espaços políticos. Inicialmente, mostro como o patrimônio passou por transformações espaciais que modificaram sua escala, indo de uma escala nacional, para uma escala mundial, seguido de uma escala regional e ao final alcançando uma escala local. Em seguida, considero como espaços políticos são fundados a partir do encontro dos atores representantes dessas diferentes escalas e apresento criticamente algumas categorias, limites e possibilidades de estudos espaciais sobre a temática patrimonial.
\end{abstract}

Palavras-chaves: Patrimônio. Escala geográfica. Espaços políticos.

\section{HERITAGE: BETWEEN GEOGRAPHICAL SCALES AND POLITICAL SPACES}

\begin{abstract}
Recently geography has come to consider patrimonialization as a factor of spatial transformations. Despite the various contributions of geographers involved in the theme, there is a lack of studies on the political aspects of heritage. The present text aims to contribute with the approximations between patrimony and geography, using the concepts of geographical scale and political spaces. Initially, I show how the heritage category has gone through spatial transformations that changed its geographical scale, going from a national scale to a world scale, followed by a regional scale and finally reaching a local scale. Then, I consider how political spaces are founded from the meeting of the actors from these different scales and critically present some categories, limits and possibilities of spatial approach on the patrimonial theme.
\end{abstract}

Keywords: Heritage. Geographical scale. Political spaces. 


\section{CONSIDERAÇÕES INICIAIS}

O presente texto tem como objetivo jogar para debate os questionamentos iniciais que fundamentam a pesquisa a ser realizada junto ao Grupo de Estudos e Pesquisas sobre Política e Território (Geoppol-UFRJ). Apesar de não apresentar resultados definitivos, espero contribuir, mesmo que timidamente, na compreensão dos vínculos entre espaço e patrimônio.

A pesquisa em questão parte da observação da falta de representação nas políticas patrimoniais. Apesar das diversas recomendações sobre o envolvimento das comunidades locais nos processos de patrimonialização propostas pela Organização das Nações Unidas para a Educação, a Ciência e a Cultura (UNESCO) e das metodologias criadas no Instituto do Patrimônio Histórico e Artístico Nacional (IPHAN), dentre outros órgãos, nota-se que a seleção e gestão de elementos valorizados ainda é uma ação restrita a um grupo de técnicos e experts.

Ao ocupar cargos públicos ou exercer consultorias, os técnicos do patrimônio fundamentam suas ações com base em seu capital simbólico, cultural e social. Eles possuem autoridade para estabelecer os limites do patrimônio em função de seus conhecimentos culturais, sociais e simbólicos, exercendo um poder simbólico (Bourdieu, 2010) na construção de um discurso autorizado do patrimônio (Smith, 2006). Como esperado nas relações de poder, esse poder simbólico não está livre de contestações e outros atores tem demandado um maior envolvimento com os bens protegidos ou proposto outras narrativas sobre determinados elementos do espaço para obter visibilidade e alcançar seus objetivos, criando insurgências patrimoniais (Castriota e Braga, 2016).

O poder simbólico dos técnicos e experts e as ações de contestação dos movimentos insurgentes não acontecem no vazio, mas ocorrem em espaços específicos. Com o avanço da democracia ao redor do globo e com as transformações enfrentadas pela categoria do patrimônio, os espaços de encontros desses diferentes atores são transformados em espaços políticos (Castro, 2012). Assim, audiências públicas, comitês de gestão ou grupos de trabalhos são locais onde atores com diferentes alcances apresentam seus interesses e entram em conflito para delimitar as razões patrimoniais a serem adotadas.

Da mesma forma, os atores envolvidos na patrimonialização e na contestação das ações não possuem alcance espacial ilimitado, mas estão restritos às limitações políticas, sociais, técnicas e econômicas que estabelecem recortes espaciais diferenciados. Cada ator possui uma escala de atuação socialmente estabelecida que também delimita o fenômeno patrimonial. As 
ações empreendidas pelos técnicos do IPHAN, por exemplo, são restritas ao território nacional, enquanto que as reivindicações de um movimento social para proteger uma paisagem histórica possuem uma abrangência, inicialmente, local.

Como esses espaços políticos são organizados? Como atores com diferentes escalas de atuação se articulam para a construção do patrimônio? Quais estratégias espaciais grupos locais utilizam para criar e ocupar espaços políticos? Essas são as questões que orientam a pesquisa que deu origem a esse texto.

O trabalho aqui apresentado terá como foco dois aspectos importantes para a pesquisa, que emergem da consideração do patrimônio como uma questão política e, por isso, possuidor de um caráter espacial (Ribeiro, 2013) e conflituoso (Gravari-Barbas e Veschambre, 2003): o papel da escala geográfica na formação da categoria do patrimônio; o surgimento dos espaços políticos do patrimônio a partir do encontro de atores atuantes em diferentes escalas.

\section{AS ESCALAS GEOGRÁFICAS DO PATRIMÔNIO}

Apesar de ser um objeto transversal às ciências sociais, o patrimônio foi reconhecido pela geografia tardiamente como uma possível fonte de compreensão das diferenças espaciais. Como observei em outro momento, apenas após a década de 2000 a geografia brasileira consagrou o patrimônio como um o tema de estudo. Anterior a este período, o tema possuía um status inferior na compreensão das transformações espaciais ocorridas no território, ficando subjugado às análises que destacavam os aspectos econômicos (Melo Filho, 2017).

Enquanto na França o patrimônio foi inserido a partir das análises de identidade e do planejamento urbano (Veschambre, 2007), a inserção do tema na geografia brasileira ocorreu de forma associada às relações com os estudos do turismo, destacando-se os trabalhos sobre a refuncionalização dos centros históricos gerados pelo aumento das práticas turísticas em função do tombamento nacional e da inscrição de bens na Lista do Patrimônio Mundial da UNESCO ou a partir da análise das forças globais de patrimonialização (Scifoni, 2003; PaesLuchiari, 2005; Costa, 2011; Sotratti, 2010; Paes, 2012; Cifelli, 2015).

Outro caminho trilhado pela geografia brasileira para analisar o patrimônio segue uma tradição relacionada ao espaço urbano. No contexto brasileiro as cidades foram os principais locais de execução das políticas de preservação nos primeiros anos do IPHAN, destacando-se os tombamentos ocorridos entre 1937 e 1969 na cidade do Rio de Janeiro, nas cidades barrocas mineiras, e nos estados da Bahia e de Pernambuco (Rubino, 1996). Em paralelo ao 
final da chamada fase heroica das práticas do IPHAN ${ }^{1}$, a geografia nacional começou a se preocupar definitivamente com os espaços urbanos, visando analisar as desigualdades sociais causadas pela globalização do mercado, elevando a geografia urbana ao nível de principal campo da ciência.

Desta forma, não é de se estranhar que a temática do patrimônio apareça anos depois associada à cidade nos grupos de trabalhos dos grandes encontros nacionais envolvendo geógrafos $^{2}$. Assim, associa-se o patrimônio ao espaço urbano, um tema clássico da geografia do século XX, para analisar as transformações populacionais e de infraestruturas geradas por projetos de recuperação ocorridas no Brasil a partir dos anos 1980. O estudo das áreas centrais das grandes metrópoles aparece como caminho para pensar os danos ao patrimônio e ao tecido social e o termo gentrification torna-se presente, sobretudo nos trabalhos mais próximos do planejamento urbano e da sociologia (Campos, 2006; Campos, 2013).

Ou seja, o patrimônio está presente nas pesquisas da geografia de forma recente e, de certa maneira, ainda restrito a algumas abordagens. Se estes trabalhos trouxeram importantes contribuições para compreendermos as relações entre a patrimonialização e o espaço geográfico, eles deixam alguns caminhos ainda pouco explorados pelos geógrafos. Dentre as várias possibilidades, destaco a ausência de trabalhos que abordem a patrimonialização enquanto um processo político transformador do espaço geográfico a partir da articulação de atores operando em diferentes escalas geográficas e espaços políticos.

Considero que uma análise da patrimonialização a partir de uma abordagem espacial significa compreender como as diferentes escalas do fenômeno estão articuladas pelos atores envolvidos. A patrimonialização não é uma abordagem unicamente nacional, produzida por atores vinculados ao território nacional, também não representa as transformações nas formas e conteúdos produzidos no espaço em função do reconhecimento de uma área pelos atores globais. Patrimonializar um elemento do espaço representa, no contexto atual, articular diferentes atores com escalas de atuação variadas.

Como os atores envolvidos com o fenômeno do patrimônio tem atuação limitada pelo pacto social que confere uma extensão às suas ações, o conceito de escala geográfica emerge

\footnotetext{
${ }^{1}$ A fase heroica do IPHAN representa o período de atuação de Rodrigo Melo Franco de Andrade, primeiro diretor do instituto. Este período $(1937$ - 1969) registra o maior número de bens tombados em toda a história do instituto e foi marcado pela superação das dificuldades técnicas e econômicas e estabelecimento das políticas de patrimônio no cenário nacional (Fonseca, 2005).

${ }^{2}$ Alguns exemplos podem ser ilustrativos: no Simpósio Nacional de Geografia Urbana (SIMPURB) de 2013 foi definido o subtema "Espaço Urbano e Patrimônio Cultural". Nos Encontros Nacionais da ANPEGE (ENANPEGE) desde 2012 o tema patrimônio está inserido no GT "Cidade, Imagem e Patrimônio". Já no Encontro Nacional de Geógrafos (ENG) de 2016, dos 12 trabalhos sobre patrimônio cultural, 11 foram apresentados no eixo temático "Cidade/Urbano". 
como essencial para auxiliar na análise da patrimonialização. Para fugir dos longos debates sobre o status ontológico do tema que rementem à um antagonismo desnecessário ou que tradicionalmente têm início com a diferenciação entre escala cartográfica e escala geográfica, acho importante delimitar logo que a escala geográfica é a medida escolhida para conferir visibilidade ao fenômeno (Castro, 2007 e 2014), o que não me impede de admitir que o próprio fenômeno possui um certo alcance espacial independente da consciência do pesquisador (Souza, 2013).

Em relação ao fenômeno patrimonial, é possível observar de início um alcance espacial estritamente vinculado aos limites nacionais. De fato, a própria origem do tema está associada ao fortalecimento do Estado-Nação no mundo Ocidental (Choay, 2006 e Poulot, 2009). Funcionários públicos como Prosper Mérimée na França ou Rodrigo Melo Franco de Andrade no Brasil organizaram serviços de proteção dos monumentos históricos entre os séculos XIX e XX, com a responsabilidade de inventariar, restaurar e conservar elementos importantes ao Estado e à Nação. O monumento histórico era importante não para a população local ou como forma de justificar um pensamento global de preservação, mas tornava-se atenção da administração pública como meio de centralizar as ações do Estado e destacar perante as outras nações os melhores elementos de cada país.

No território francês, por exemplo, Eugéne Viollet-Le-Duc ficou conhecido por realizar restauros em igrejas e sítios significativos para o país, como a Catedral de NotreDame em Paris ou a Cidade de Carcassone. No Brasil, um conjunto de intelectuais como Lúcio Costa, Manuel Bandeira, Gilberto Freyre, entre outros, tornaram-se os arquitetos da memória nacional (Chuva, 2009), ao justificarem a proteção das cidades mineiras barrocas, dos conjuntos coloniais e das igrejas católicas espalhadas pelo território nacional a partir de uma retórica da perda (Gonçalves, 1996).

Em comum, esses técnicos tinham como limites de suas ações as fronteiras nacionais. Mesmo que eles frequentemente realizassem viagens ou trocassem cartas com outros técnicos, seus estudos, decisões e relatórios só tinham aplicações efetivas nos limites do território de cada Estado. O fenômeno patrimonial tinha neste período uma extensão nacional, com cada Estado territorial possuindo seu instituto do patrimônio.

Com pouca ou nenhuma atuação de organizações locais ou regionais, o fenômeno patrimonial torna-se global a partir de 1972. Apesar dos sucessivos encontros internacionais, das cartas de recomendações e das ações coletivas realizadas para recuperação da cidade de Veneza e dos templos egípcios de Abu Simbel (Silva, 2012), uma escala global do patrimônio 
surge a partir da Convenção para Proteção do Patrimônio Mundial, Cultural e Natural de 1972 da UNESCO. Este documento é o primeiro acordo global entre Estados destinado à proteção de elementos representativos para toda humanidade e, surgindo no contexto das convenções ambientais (Pressouyre, 1993), cria um dispositivo global que organiza todo um sistema internacional.

Como tentei apresentar em outro momento (Melo Filho, 2017), o dispositivo do patrimônio mundial se organiza a partir de uma diversidade de normas e conceitos, produzidos pela disputa entre atores em busca por inserir temas e elementos no acordo global de Estados que forma a Convenção de 1972. A consolidação dessas normas e conceitos estabeleceu um verdadeiro manual do patrimônio, composto por siglas de instituições envolvidas, de nomes de personagens, de expressões e conceitos específicos, e de exemplos de sucesso organizado na Lista do Patrimônio Mundial. Esse manual é a expressão de um campo do saber, organizado pelo grupo dos experts do patrimônio mundial. Esse grupo de técnicos elevados à uma categoria específica é fundamental para a aplicação do dispositivo patrimonial e são eles os responsáveis por construir ou prestar consultorias para a construção dos dossiês de candidatura de um bem à Lista do Patrimônio Mundial; inseridos nos Advisory Bodies eles produzem as avaliações sobre determinadas candidaturas; Têm voz ativa nas reuniões do Comitê do Patrimônio Mundial na defesa da inscrição de bens; A partir de encontros internacionais eles definem os conceitos a serem inseridos na Orientações; enfim, este grupo possui o poder simbólico para definir os limites de aplicação do patrimônio em escala global.

Em um contexto mais recente, o fenômeno patrimonial se apresenta e se conforma a partir das escalas regionais e locais. O fenômeno passa a ser regional a partir do momento que instituições vinculadas a outras delimitações territoriais começam a atuar na produção de ações de conservação, identificação e valorização de elementos significativos à uma região.

As organizações em 2012 da Comissão de Patrimônio Cultural no âmbito do Mercosul Cultural, bem como a publicação da Convenção de Faro, em 2005, no âmbito do Conselho da Europa, representam dois exemplos de integração regional que utilizam do patrimônio como meio de fortalecer grupos políticos maiores. No primeiro exemplo, o reconhecimento da Ponte Internacional Barão de Mauá em 2015 como primeiro bem binacional reconhecido pelo Mercosul Cultural considerou na proteção do bem os valores associados a expressão comum da região perante o mundo, e o fato dela representar os esforços de união regional. 
A afirmação da escala regional, também pode ser observada a partir do surgimento dos Centros de Categoria 2 relacionados ao patrimônio. Apesar de estarem sediados em países específicos, a atuação destes centros é voltada a implementação em regiões que não seguem os padrões geográficos ou da UNESCO. Por exemplo, o Centro Lúcio Costa, com sede no Brasil, tem área de atuação na América do Sul e nos territórios de países de língua oficial portuguesa na África e Ásia, desenvolvendo ações de cunho regional e contribuindo para a articulação dos países envolvidos. O patrimônio assume, nessa escala, um contexto geopolítico, por ser utilizado como meio de promoção da integração regional e como instrumento de afirmação do poder de um Estado sobre outro.

Já o contexto local torna-se outro nível de apreensão do fenômeno patrimonial recentemente. Como apontaram Zancheti e Hidaka (2012), os envolvidos com o patrimônio assumem um caráter vasto, sobretudo quando observamos o patrimônio mundial, já que, ao menos teoricamente, ele interessa a toda humanidade. De difícil delimitação, a escala local do patrimônio é aquela referida às populações que possuem relação política direta com o bem, ou seja, não basta apresentar uma relação simbólica, mas é necessário buscar modificações na agenda política através do patrimônio. Como esforço analítico de construção da pesquisa, considero que a escala local do patrimônio diz respeito aos grupos sociais organizados politicamente (ONG's, instituições comunitárias, grupos culturais, etc.) que participam da construção da narrativa que valorizou o bem ou aqueles que, excluídos do processo, ocupam determinados espaços para contestar as ações públicas.

Como comentou Bortolotto (2011) e Heinich (2009), a escala local das populações tradicionais ou dos grupos culturais passou a interessar às políticas de patrimônio com o advento do patrimônio imaterial, atribuindo a categoria patrimonial uma outra função. Se no início os grupos de técnicos e de experts delimitavam o patrimônio em um processo de cima para baixo, com o patrimônio imaterial a população local ganha voz ativa no processo e os técnicos passam a ser apenas mediadores dos valores atribuídos aos bens.

Por outro lado, acho inegável que o fenômeno patrimonial assume uma abrangência local em paralelo com os avanços da democracia mundial, que cria novos espaços políticos e confere maior possibilidade de participação das sociedades (Castro, 2012 e 2013). Apesar disto, como o sistema de representação política não consegue atender todas as diferenças sociais e territoriais existentes, a falta de representatividade da sociedade nesses espaços instituídos levou alguns grupos a executar uma série de "ações diretas", ocupando e 
reutilizando espaços públicos e edifícios de valor patrimonial, recolocando em questão o direito à cidade e à memória (Castriota e Braga, 2016).

\section{ESPAÇOS POLÍTICOS DO PATRIMÔNIO}

Como tentei mostrar no tópico anterior, o fenômeno do patrimônio pode ser observado a partir de 4 escalas geográficas: A escala local, de atuação dos atores politicamente organizados em torno de um bem; a escala nacional, dos institutos de patrimônio vinculados ao Estado; a escala regional, dos conjuntos de países e instituições que definem elementos comuns com base em uma narrativa; e a escala global, organizada a partir da Convenção de 1972 da UNESCO. Cada uma dessas escalas pode apenas ser observada a partir do conjunto de instituições, normas e atores que delimitam suas abrangências de atuação e podem, em muitos momentos, se associarem na patrimonialização ou contestação de um bem.

Essas atuações, porém, não ocorrem no vazio, mas em espaços específicos, estabelecidos por dispositivos legais ou construídos a partir de ações diretas no espaço. Quando estes diferentes atores de abrangências variadas se encontram, fundam-se espaços políticos (Castro, 2012).

Como considero o patrimônio como um fenômeno político (Ribeiro, 2013), parto do princípio que ele qualifica o espaço geográfico, tornando-o um território de disputas e conflitos, assumindo um caráter não consensual (Gravari-Barbas e Veschambre, 2003). Assim, a qualificação do espaço pela política surge quando há uma materialidade, uma imaterialidade e uma intencionalidade.

No caso dos espaços políticos do patrimônio a materialidade é expressa nos espaços destinados à construção de narrativas patrimoniais ou definição de parâmetros de gestão. A materialidade dos espaços políticos também pode ser observada nas assembleias públicas destinadas à apresentação das decisões tomadas, ou nos dos grupos de trabalhos internos que se estabelecem para tratar de um elemento.

A imaterialidade desses espaços é traduzida a partir dos poderes simbólicos (Bourdieu, 2010) que cada um dos atores possui. Um técnico do patrimônio apresenta elevado capital cultural em função de sua trajetória acadêmica e profissional para definir a não proteção de um bem, por outro lado, o representante de um movimento social possui elevado capital social 
e pode reivindicar a proteção do bem com o apoio de seus pares. As posições de cada um dos atores se altera na medida com que o poder simbólico deles é alterado.

Já a intencionalidade dos espaços políticos ocorre pela coletividade humana em busca de modificar a agenda política. Em busca pela conexão entre sociedade e Estado, espaços públicos transformam-se em espaços políticos, isto é, espaços políticos constituídos pela relação entre livres e diferentes e pelo conflito de interesses (Machado Filho, 2017). Quando um movimento social ocupa uma praça para reivindicar a preservação de determinados monumentos históricos, aquela praça deixa de ser um local com a visibilidade como principal atributo (Gomes, 2013) e torna-se um espaço onde a política é o qualificador.

Aqui é importante um esforço de delimitação maior, primeiramente para indicar o que não se configura como um espaço político. O Conselho Consultivo do IPHAN, órgão que reúne diferentes técnicos e experts para a seleção dos patrimônios culturais e imateriais do Brasil se reúne 4 vezes ao ano e possui uma materialidade, afinal ele ocorre em locais específicos. $\mathrm{O}$ espaço do conselho também é permeado por imaterialidades, onde cada ator utiliza de seu poder simbólico para alcançar objetivos variados e muitas vezes conflitantes, estabelecendo acordos e contrariando interesses muitas vezes maiores, como interesses privados, por exemplo. Porém, o Conselho Consultivo do IPHAN não está aberto à sociedade, já que seus integrantes são selecionados pelo presidente do Instituto. Assim, ausente a escala do local, não pode haver uma aproximação entre sociedade e Estado, descaracterizando o espaço político.

É importante também destacar que a intencionalidade do espaço difere um pouco do conceito de "emoção patrimonial" apresentado por Fabre (2013), relacionado a uma etapa prévia do fazer político. Antes da organização política, as populações utilizam de suas emoções para justificar suas ações. Assim, o ato de se amarrar ao portão de uma igreja para impedir sua destruição, por mais que ele seja um ato político, não estabelece ali um espaço qualificado pela política, mas sim um espaço emotivo. O papel das normas e das instituições, ausente das abordagens mais emotivas, é considerado como fundante dos espaços políticos, pois elas garantem a isonomia teórica dos participantes. Claro está, porém, que a partir de uma emoção patrimonial pode-se fundar espaços políticos, onde a ocupação do Cine Olinda (PE) em 2016 é um exemplo.

Em resumo, os espaços políticos do patrimônio, estabelecidos a partir de uma materialidade, imaterialidade e intencionalidade, são os locais de produção dos conflitos das diferentes escalas geográficas patrimoniais. 
Após essa breve delimitação do que considero os espaços políticos do patrimônio, é importante pensar como é possível estudar esses locais. Machado Filho (2017) apresentou como proposta as seguintes categorias de análise dos espaços políticos: arena, atores, ação, ritual e processo.

A categoria da arena busca contrapor a noção ainda muito presente que compreende a dimensão espacial da política através da figura do espaço enquanto mero palco das ações. A ideia da arena como uma categoria do espaço político atende aqui a um significado mais complexo e abrangente e atribui ao espaço um caráter ativo. Compreende-se, assim, que a organização do espaço influencia as ações tomadas nos espaços de decisão. Dessa maneira, analisar a arena dos espaços políticos significa analisar os lugares ocupados e a organização interna desses lugares. Os atores são aqueles que ocupam e formam esses espaços. Já a ação diz respeito a intencionalidade da organização. O ritual perpassa a liturgia parlamentar ou a manifestação política e o processo refere-se ao processo legislativo ou à mobilização de grupos sociais.

Machado Filho (2017) considera apenas em sua análise os espaços políticos exclusivos (que no caso dele são as Casas Legislativas) e os espaços políticos abertos (ruas e praças). Porém, em relação ao patrimônio essas delimitações não bastam. Os atores, ações, rituais e processos são diferentes dos contextos analisados. Enfim, o próprio espaço político é outro.

É importante pensar que determinados atores possuem poder simbólico com alcance espacial diferenciado em função dos espaços políticos acionados. Assim, um expert da UNESCO que participa do Comitê de Gestão de um bem terá capital simbólico maior quando estiver localizado em espaços políticos constituídos em países periféricos, onde os técnicos nacionais não possuem o mesmo capital cultural.

Em relação aos espaços políticos abertos do patrimônio, é possível considerar que o ritual e o processo assumem maior importância em função da carga simbólica dos elementos de reivindicação. Assim, devido à importância atribuída a determinados elementos que compõem a pauta dos grupos de escala local, as reivindicações podem alcançar espaços globais, ampliando a formas de mobilização e a escala do ritual político.

\section{CONCLUSÃO}

O presente texto apresentou reflexões iniciais sobre as relações entre patrimônio, escala geográfica e espaços políticos. Busquei introduzir o debate sobre as extensões espaciais 
do fenômeno patrimonial e mostrar que o tema, enquanto um fenômeno político, se produz em espaços qualificados pela política.

Mostrei que o fenômeno patrimonial abarcou diversas escalas geográficas, em função da abrangência das instituições e dos atores envolvidos com a temática. Em função das transformações da categoria, o patrimônio passou da escala nacional para a mundial, para em seguida ter um alcance regional e local.

É importante deixar claro que o surgimento de novas escalas patrimoniais, não apagou a existência de outras. A escala do nacional, por exemplo, não deixou de existir com o surgimento da Convenção da UNESCO de 1972. Na verdade, a partir da globalização do patrimônio ocorreu, inicialmente, uma afirmação dos patrimônios nacionais adequados pelos parâmetros internacionais. Assim, em um contexto onde a globalização começava a surgir como possível enfraquecedora dos Estados nacionais, o patrimônio de escala global surgiu para valorizar os territórios nacionais pela escolha dos elementos mais significativos de sua história e cultura.

Ou seja: o patrimônio no contexto atual apresenta-se como um processo composto por atores relacionados às múltiplas escalas geográficas que vão do local ao mundial, passando pelo regional e o local, atuando na construção de discursos autorizados do patrimônio ou em sua contestação. Essas múltiplas escalas do fenômeno impõem diferentes arranjos e recortes territoriais, muitas vezes sobrepostos ou conflitantes.

Esses conflitos compõem uma marca intrínseca ao fenômeno do patrimônio e ocorrem nos espaços políticos, locais onde os atores com diferentes abrangências de atuação se localizam. São nesses espaços onde o fazer político e o patrimônio se reproduzem, alterando o espaço geográfico a partir da política.

Neste sentido, torna-se fundamental compreender como esses espaços políticos são formados e de que maneira eles estão organizados, quais atores, ações, rituais e processos compõem esses lugares e como atores com diferentes escalas geográficas e capital simbólico são confrontados.

Uma geografia política do patrimônio deve analisar como diferentes recortes territoriais são produzidos entre os atores envolvidos no processo patrimonialização e a análise dos espaços políticos pode servir como um caminho de análise dessas questões. 


\section{REFERÊNCIAS}

BORTOLOTTO, C. Le trouble du patrimoine culturel imatériel. In: BORTOLOTTO, C. Le patrimoine culturel immatériel: Enjeux d'une nouvelle catégorie. Paris: Maison Des Sciences de L'homme, 2011. p. 21-46.

BOURDIEU, P. O poder simbólico. Rio de Janeiro: Bertrand Brasil, 2010.

CAMPOS, H. R. Transformações urbanas recentes em Tiradentes-MG: anos 80 e 90 do século XX. Dissertação de Mestrado - Departamento de Geografia, USP, 2006.

. Gentrificação na área central de Tiradentes/Mg. Mercator, Fortaleza, v. 12, n. 29, p.69-87, 2013.

CASTRIOTA, L.; BRAGA, G.. Patrimônio insurgente: estetização e resistência cultural no Brasil do início do Século XXI. In: CONTESTED_CITIES, 1., 2016, Madrid. CONGRESO INTERNACIONAL CONTESTED_CITIES EJE 5. Madrid: Publicaciones Contested Materiales 2016, 2016. p. 1 - 14. Disponível em: <http://contested-cities.net/working-papers/ wp-content/uploads/sites/8/2016/07/WPCC-165549-BarciBraga-PatrimonioInsurgente.pdf>. Acesso em: 16 mar. 2017.

CASTRO, I. E. de. O problema da escala. In: CASTRO, Iná Elias de; GOMES, Paulo Cesar da Costa; CORRêA, Roberto Lobato. Geografia: Conceitos e temas. 10. ed. Rio de Janeiro: Bertrand Brasil, 2007. p. 117-140.

. O espaço político: limites e possibilidades do conceito. In: CASTRO, Iná Elias de; GOMES, Paulo Cesar da Costa; CORRêA, Roberto Lobato. Olhares geográficos: modos de ver e viver o espaço. Rio de Janeiro: Bertrand Brasil, 2012. p. 43-72.

A democracia como um problema para a geografia: o fundamento territorial da política. In: CASTRO, Inás Elias de; RODRIGUES, Juliana Nunes; RIBEIRO, Rafael Winter. Espaços da Democracia: Para a agenda da Geografia Política contemporânea. Rio de Janeiro: Bertrand Brasil, 2013. p. 9-33.

Escala e pesquisa na geografia. Problema ou solução? Espaço Aberto, Rio de Janeiro, v. 4, n. 1, p.87-100, jan. 2014.

CHOAY, F. A alegoria do patrimônio. 3. ed. São Paulo: Unesp, 2006. 282 p.

CHUVA, M. R. R. Os arquitetos da memória: sociogênese das práticas de preservação do patrimônio cultural no Brasil (anos 1930-1940). Rio de Janeiro: Ed. UFRJ, 2009 
CIFELLI, G. Turismo, patrimônio e novas territorialidades em Ouro Preto-MG. 2015. 377 f. Tese (Doutorado) - Curso de Geografia, Instituto de Geociências, Universidade Estadual de Campinas, Campinas, 2015.

COSTA, E. B. da. Totalidade urbana e totalidade-mundo: as cidades coloniais barrocas face à patrimonialização global. 2011. 445 f. Tese (Doutorado) - Curso de Geografia, Faculdade de Filosofia, Letras e Ciências Humanas, Universidade de São Paulo, São Paulo, 2011.

FABRE, D.. Le patrimoine porté par l'emótion. In: FABRE, D. Émotions patrimoniales. Paris: Maison Des Sciences de L'homme, 2013. p. 13-100. (Ethnologie de la France).

FONSECA, M. C. L. da. O patrimônio em processo. Trajetória da política federal de preservação no Brasil. 2a Ed. Rio de Janeiro: EdUFRJ, IPHAN, 2005.

GOMES, P. C. da C. O lugar do olhar: elementos para uma geografia da visibilidade. Rio de Janeiro: Bertrand Brasil, 2013.

GONÇALVES, J. R. S. A Retórica da perda: os discursos do patrimônio cultural no Brasil. Rio de Janeiro: UFRJ, 1996.

GRAVARI-BARBAS, M.; VESCHAMBRE, V. Patrimoine: derrière l'idée de consensus, les enjeux d'appropriation de l'espace et des conflits In: Conflits et territoires. Tours: Presses universitaires François Rabelais, 2003, p. 67-82

HEINICH, N. La Fabrique du patrimoine: De la cathédrale à la petite cuillère. Paris: Maison Des Sciences de L'homme, 2009. 286 p. Ethnologie de la France.

MACHADO FILHO, G. F. Espaços da Política: a relação entre o espaço político das assembleias e o espaço político das ruas no contexto das manifestações políticas brasileiras contemporâneas. 2017. 107 f. Dissertação (Mestrado) - Curso de Geografia, Universidade Federal do Rio de Janeiro, Rio de Janeiro, 2017.

MELO FILHO, D. C. de. Patrimônio como Recurso Político: Disputas Por Reconhecimento, Fortalecimento E Geopolítica Entre Unesco E Cabo Verde. 2017. 236 f. Tese (Doutorado) - Curso de Geografia, Universidade Federal do Rio de Janeiro, Rio de Janeiro, 2017.

PAES, M. T. D. Refuncionalização turística de sítios urbanos históricos no Brasil: Das heranças simbólicas à reprodução de signos culturais. Geografia, Rio Claro, v. 37, n. 2, p.319-334, maio 2012. 
PAES-LUCHIARI, M. T. D. Centros históricos: Mercantilização e territorialidades do patrimônio cultural urbano. Geographia: Revista de pós-graduação em Geografia, Niterói, v. 7, n. 14, p.25-41, jun. 2005.

POULOT, D. Uma história do patrimônio no Ocidente, séculos XVIII - XXI: do monumento aos valores. São Paulo: Estação Liberdade, 2009. 239 p.

PRESSOUYRE, L. La Convention du patrimoine mondial, vingt ans après. Paris: Unesco, 1993.

RIBEIRO, R. W. Paisagem, patrimônio e democracia: novos desafios para políticas públicas. In: CASTRO, Iná Elias de; RODRIGUES, Juliana Nunes; RIBEIRO, Rafael Winter. Espaços da democracia: Para a agenda da Geografia Política contemporânea. Rio de Janeiro: Bertrand Brasil, 2013. p. 158-176.

RUBINO, S. “O mapa do Brasil passado”. In: Revista do Patrimônio Histórico e Artístico Nacional. 24, 1996, pp. 97- 105.

SCIFONI, S. Patrimônio Mundial: Do ideal humanista à utopia de uma nova civilização. Geousp: Espaço e Tempo, São Paulo, v. 1, n. 14, p.77-88, jul. 2003.

SILVA, F. F. da. As cidades brasileiras e o patrimônio cultural da humanidade. 2. ed. São Paulo: Edusp, 2012.

SMITH, L. Uses of Heritage. Nova Iorque: Routledge, 2006.

SOTRATTI, M. A. Imagem e Patrimônio Cultural: as Ideologias Espaciais do Patrimônio Turistificado na Promoção Turística internacional do Brasil - EMBRATUR 2003-2010. 2010. 253 f. Tese (Doutorado) - Curso de Geografia, Universidade Estadual de Campinas, Campinas, 2010.

SOUZA, M. L. de. Escala geográfica, “construção social da escala" e política de escala". In: Souza, Marcelo Lopes de. Os conceitos fundamentais da pesquisa sócio-espacial. Rio de Janeiro: Bertrand Brasil, 2013; p. 179-216

VESCHAMBRE, V. Patrimoine: Un objet révélateur des évolutions de la géographie et de sa place dans les sciences sociales. Annales de Géographie, Paris, v. 656, n. 4, p.361-381, out. 2007.

ZANCHETI, S. M.; HIDAKA, L. T.. An indicator for measuring the state of conservation of urban heritage sites. In ZANCHETI, Sílvio Mendes; SIMILÄ, Katriina (orgs.). Measuring heritage conservation performance, Rome, ICCROM, 2012, p. 252-264. 